\title{
ON SUB-STRUCTURE AND TEXTURE DEVELOPMENT IN WARM ROLLED COPPER
}

\author{
E. C. H. LIM and B. J. DUGGAN \\ Department of Mechanical Engineering, University of Hong Kong, Pokfulam Road, \\ Hong Kong
}

(Received 20 January 1996)

\begin{abstract}
Preliminary results on the effects of rolling strain rate and deformation temperature on warm rolled copper are presented. It is shown that in single pass rolling the textures are less intense than those produced by homogeneous rolling over the temperature range $30^{\circ} \mathrm{C}-500^{\circ} \mathrm{C}$. Deformation banding is present in homogeneous rolling at room temperature and in single pass rolling at $500^{\circ} \mathrm{C}$ and is drastically reduced in single pass rolling at $30^{\circ} \mathrm{C}-350^{\circ} \mathrm{C}$. The results are discussed in terms of slab widening, rate and temperature effects on slip processes.
\end{abstract}

KEY WORDS: Copper, rolling, single pass, homogeneous, temperature dependence, strain rate dependence, deformation banding

\section{DEDICATION}

Hsun "Bill" Hu was active in texture research for all of his long career, and he made many highly significant contributions to the field. These contributions are too many to be listed here, but both the Citation Index and this volume of the journal of which he was a founding editor bear eloquent testimony to his science and dedication to the task of solving texture problems. In addition, he was personally kind and warm to new colleagues and took great pleasure in encouraging $\mathrm{PhD}$ students in their research. $\mathrm{He}$ will be greatly missed by the texture community at large and by all who knew him personally.

\section{INTRODUCTION}

Barrett (1938) pointed out that deformation banding (DB) seemed to be a widespread phenomenon in heavily deformed single and poly-crystals, and should be included in any model of plastic deformation. Chin (1965) later showed how this might be done in a Taylor framework and this approach was used by Lee et. al. (1993a) to improve the correspondence between simulated and measured textures in polycrystalline FCC metals. However, this line of research stretching from Barrett to Lee et. al. does not include the effects of strain rate. That it was important was demonstrated by $\mathrm{Hu}$ and Cline (1965) who compressed Fe-3\%Si single crystals of cube orientation at either $10^{-2} \mathrm{sec}^{-1}$ or $10^{+3} \mathrm{sec}^{-1}$ and showed deformation bands subdividing the crystals at the low rate of straining but not at the highest rates. They concluded that plastic flow was less turbulent at high rates of straining. The textures showed great differences, the 


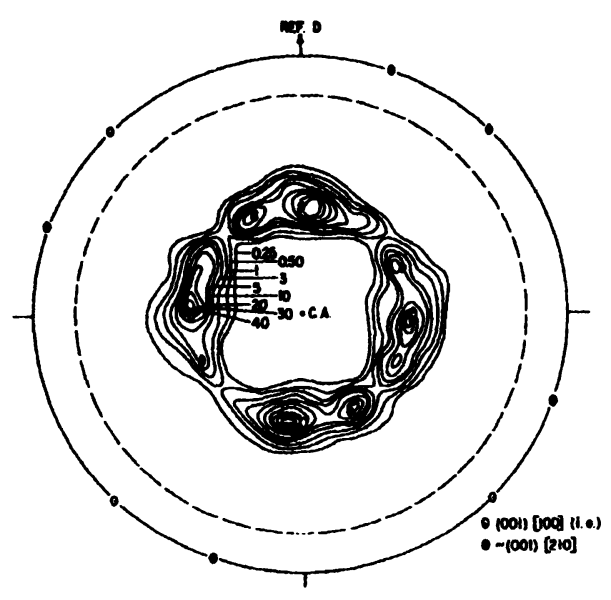

(a)

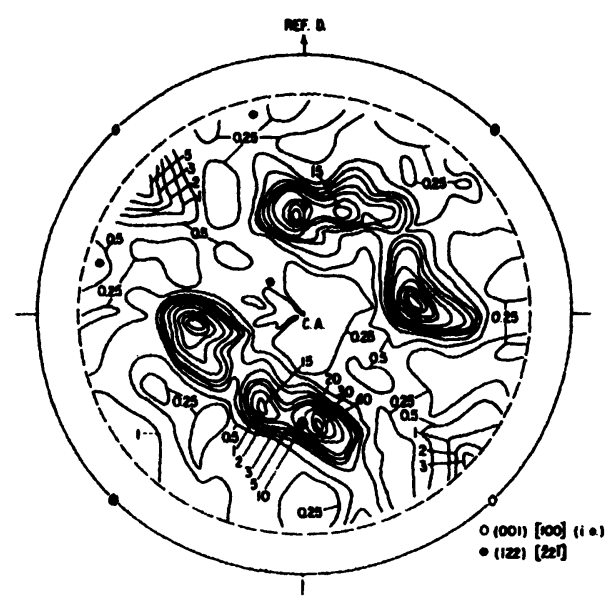

(b)

Figure 1110 pole figures of $\mathrm{Fe}-3 \% \mathrm{Si}$ compressed to $80 \%$ reduction at a strain rate of

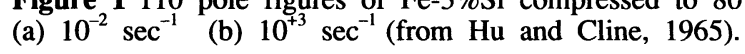

deformation banded crystal having two sharp components while the rapidly compressed crystal had a wider spread around $\{100\}<001>$, Figure 1 .

The work reported here arose from a desire to check the effects of temperature on deformation banding, for it is predicted by Lee et. al. (1993b) that DB should be enhanced at high temperatures. In order to explore this prediction it was considered necessary to use single pass rolling as interpass periods in multipass rolling would allow other processes to obscure the rolling structure development. The results were not explicable by reference to temperature effects alone, and so rate of deformation was considered. The results resembled, to some extent, those observed by $\mathrm{Hu}$ and Cline 30 years ago.

\section{EXPERIMENTAL}

Copper bar $7.5 \mathrm{~mm}$ in thickness was carefully prepared to have a uniform grain size of $100 \mu \mathrm{m}$, and made into specimens $40 \times 20 \times 7.5 \mathrm{~mm}$ with one end tapered. A modified Robertson 2 High Mill of $154 \mathrm{~mm}$ diameter was used for the rolling experiment. Due to the fact that it was not possible to measure the real temperature during rolling, as any embedded thermocouple failed in the roll gap, the temperature of the sample was measured by a non-contacting fast response infra-red thermal sensor at the entrance of the rolls. This kind of infra-red thermal sensor is capable of measuring the temperature to $95 \%$ of target temperature within 0.24 second. The emissivities of the sample at different temperatures were measured to take into account the effect of oxide formed on the sample surface which affects the indicated temperatures during warm rolling. Hot oil was poured onto the rolls before rolling to pre-heat the rolls and also to act as a lubricant. A stainless steel stage heated to the sample temperature was also used to stabilize the specimen temperature before rolling. Rapid quenching 
was achieved by having the emergent hot specimen penetrate into a plastic bag full of icy water molded to the rolls. Single pass rolling to $75 \%$ reduction in thickness was possible at inlet temperatures of $350^{\circ} \mathrm{C}$ and above, but at room temperature, a maximum of only $50 \%$ reduction was possible. Slab widening was measured in all cases, as was the exit temperature without quenching. Homogeneous rolling for comparative purposes was also done, the definition of homogeneous rolling being that given by Lee et. al. (1991). The strain rate for rolling under homogeneous conditions was calculated based on an equation given by Harris (1983) and for single pass rolling was estimated from a computer simulation. The results were $6 \mathrm{sec}^{-1}$ for homogeneous rolling, $20 \mathrm{sec}^{-1}$ for $50 \%$ and $25 \mathrm{sec}^{-1}$ for $75 \%$ single pass rolling. Pole figures were measured by the reflection method, and ODFs calculated from three independent reflections, 111, 200 and 220. Köhlhoff etching was used to reveal continuous orientation patterns across the samples and TEM was used for detailed microstructure analysis.

\section{RESULTS AND DISCUSSION}

\section{Slab Widening:}

The extent of widening under the different conditions of rolling are shown in Table 1. Slab widening is well known and recent work by Raghunathan and Sheppard (1989) shows that the process is complex and difficult to fully evaluate. Their equation contains several parameters which can only be measured rather than deduced. Nevertheless it seems beyond doubt that the process is dominated by geometrical factors such as roll diameter, draft, original width and thickness and temperature, rather than material characteristics, unless these produce pronounced frictional effects. As far as this paper is concerned, slab widening is important in that it implies a departure from plane strain conditions.

\section{Textures:}

ODFs for samples deformed 50\% under a variety of conditions are shown in Figure 2. The homogeneously rolled sample showed a standard texture, but the single pass room temperature result (Figure $2 \mathrm{~b}$ ) shows identical components in a much flatter texture. The 'flat' texture is found also at $350^{\circ} \mathrm{C}$ and $500^{\circ} \mathrm{C}$ when single pass rolling was performed, Figure $2 \mathrm{c}$ and $2 \mathrm{~d}$. As expected, homogeneous rolling to $75 \%$ reduction in thickness produced strengthening of the major texture components $\mathrm{C}, \mathrm{B}$, and $\mathrm{S}$,

Table 1 Comparison of slab widening under different rolling conditions

\begin{tabular}{lcccc}
\hline $\begin{array}{l}\text { Rolling } \\
\text { Conditions }\end{array}$ & $\begin{array}{c}\text { Homogeneous } \\
\text { Room Temp. }\end{array}$ & Room Temp. & $\begin{array}{c}\text { Single Pass } \\
\text { at } 350^{\circ} \mathrm{C}\end{array}$ & at $500^{\circ} \mathrm{C}$ \\
\hline $50 \%$ & $4 \%$ & $15 \%$ & $22 \%$ & $22 \%$ \\
$75 \%$ & $6 \%$ & - & $37 \%$ & $33 \%$ \\
\hline
\end{tabular}




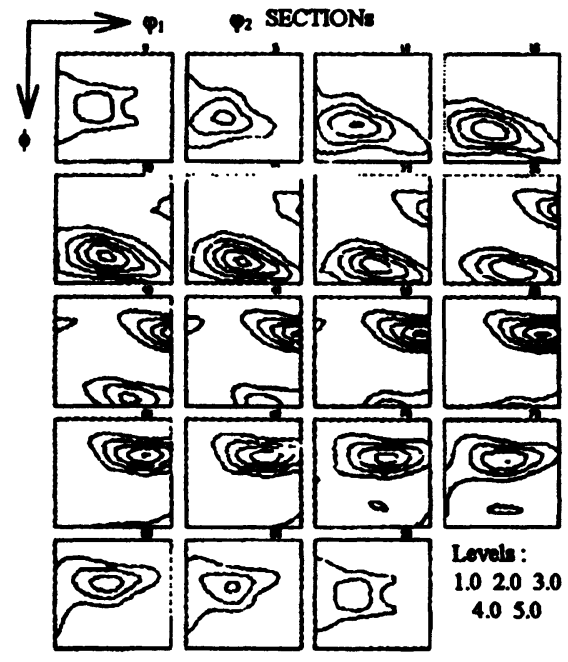

(a)

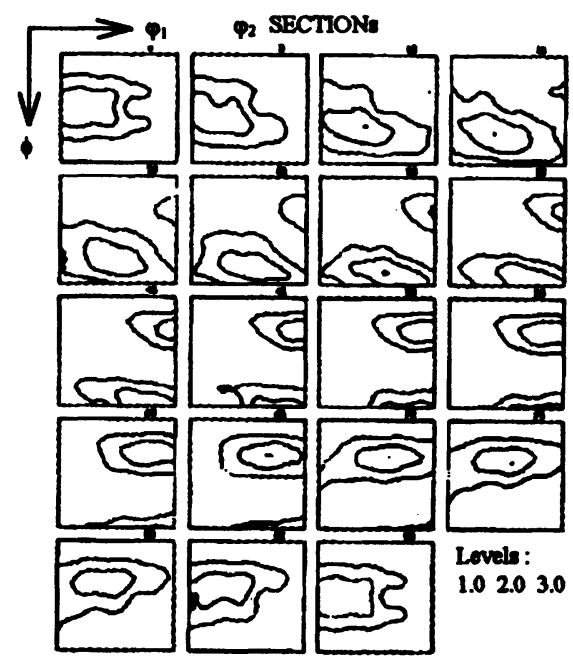

(c)

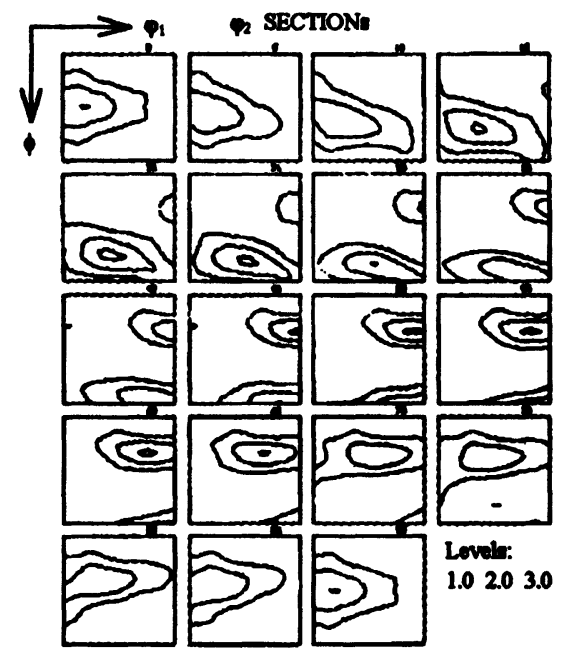

(b)

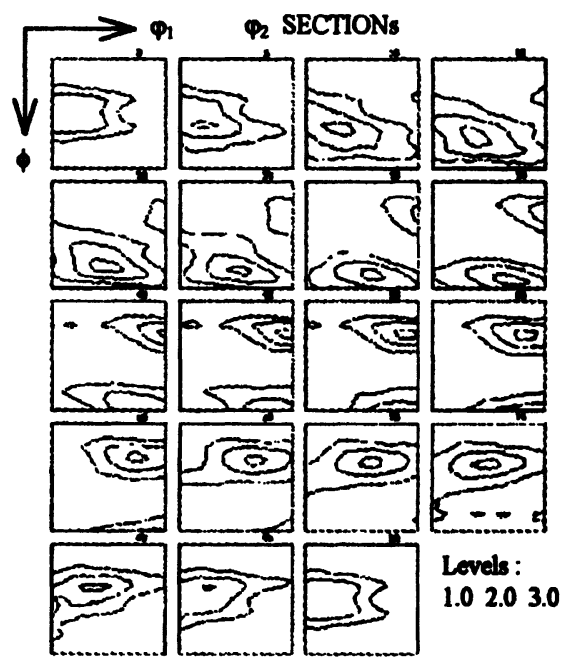

(d)

Figure 2 ODFs of sample rolled to $50 \%$
(a) homogeneously at room temperature.
(b) in single pass at room temperature.
(c) in single pass at $350^{\circ} \mathrm{C}$.
(d) in single pass at $500^{\circ} \mathrm{C}$. 
Figure 3a. However, the textures obtained at $350^{\circ} \mathrm{C}$ and $500^{\circ} \mathrm{C}$ for single pass rolling show a new trend, the higher temperature texture is stronger than that obtained at $350^{\circ} \mathrm{C}$, cf. Figure $3 \mathrm{~b}$ and $\mathrm{c}$. This is unexpected. The result cannot be explained by slab widening alone, as this was almost identical for $350^{\circ} \mathrm{C}$ and $500^{\circ} \mathrm{C}$ cases, Table 1 . Furthermore, the $350^{\circ} \mathrm{C}$ texture is different from the homogeneous rolling texture and $500^{\circ} \mathrm{C}$ single pass case. These latter textures, Figure $3 \mathrm{a}$ and c, show similar components but the $350^{\circ} \mathrm{C}$ case has a well developed $\alpha$ fibre, running from $G$ to $B$ to $\{110\}<110>$, Figure $3 b$.

It is safe to conclude from Figure 2 and 3 that either strain rate or slab widening or both are responsible for the reduction in texture intensity, but it is clear that temperature of rolling cannot be responsible for this effect. Clearly, departure from plane strain conditions should strongly affect textures, but also rate of deformation is known to have an effect as well, as was demonstrated by $\mathrm{Hu}$ and Cline (1965). Work is underway to separate these variables by simulating the textures under slab widening conditions using the standard rate independent model. The increase in texture sharpness shown in Figure 3c, however, occurs under identical slab widening conditions, and is therefore caused by the increase in deformation temperature.

\section{MICROSTRUCTURES}

Figure 4 shows crystallographically etched longitudinal sections taken from the centre of homogeneous and single pass rolled specimens to $50 \%$ reduction at room, $350^{\circ} \mathrm{C}$ and $500^{\circ} \mathrm{C}$ temperatures. When the grain thicknesses are compared, it can be seen that there are large unbanded grains distributed over the entire section in all four samples. The thickness of these grains corresponds to the expected size after homogeneous deformation. In contrast, other bands, far below the expected grain thickness are assumed to be deformation bands. It is clear that the single pass structures obtained at $500^{\circ} \mathrm{C}$

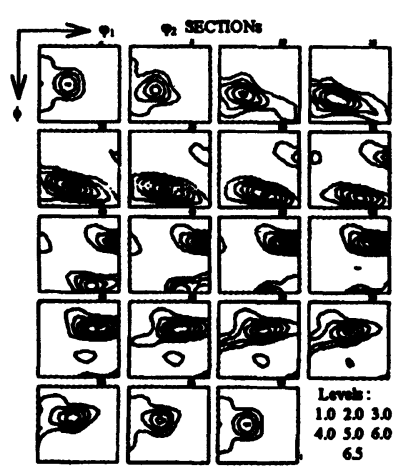

(a)

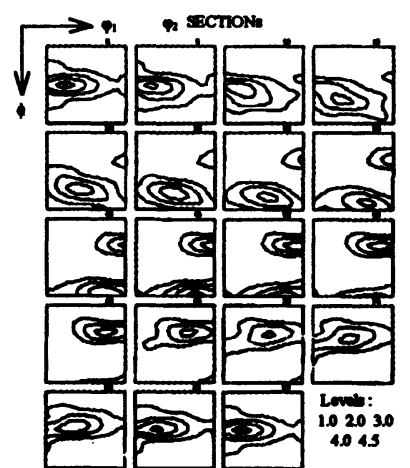

(b)

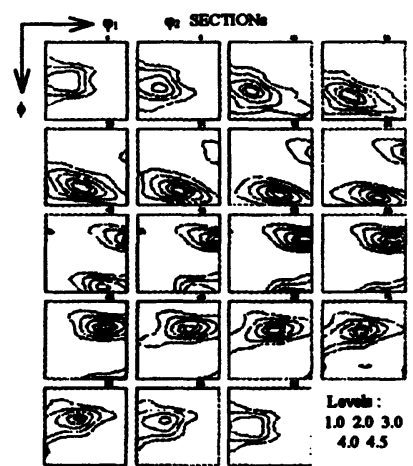

(c)

Figure 3 ODFs of sample rolled to $75 \%$

(a) homogeneously at room temperature.

(b) single pass at $350^{\circ} \mathrm{C}$.

(c) single pass at $500^{\circ} \mathrm{C}$. 


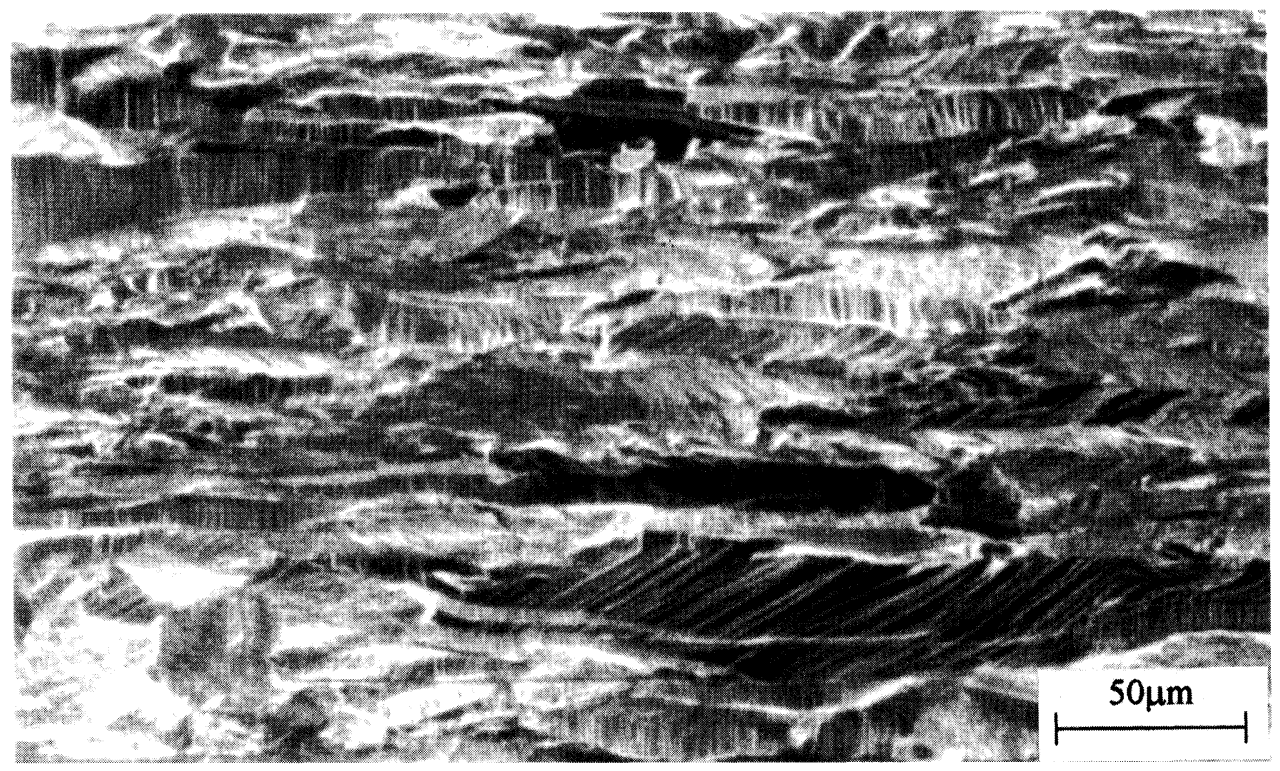

Figure 4 (a) Crystallographically etched microstructures of copper rolled to 50\% reduction homogeneously at room temperature.

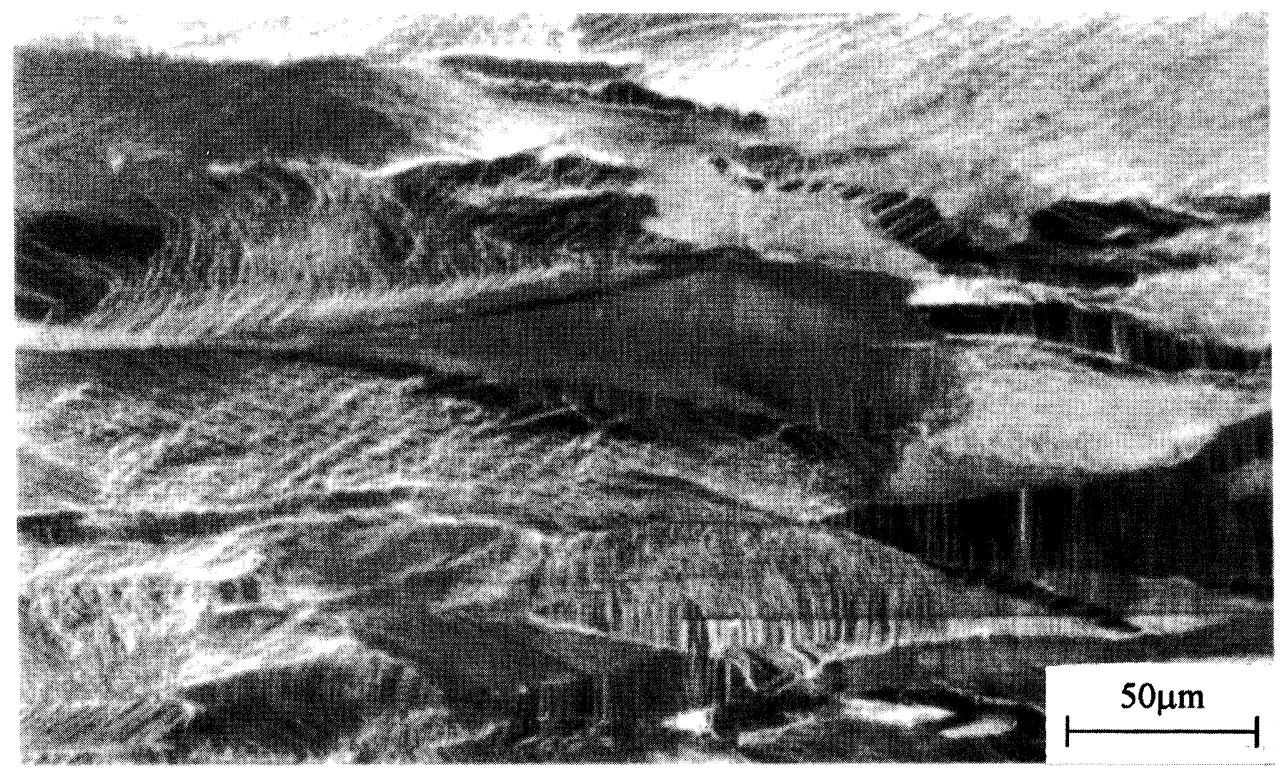

Figure 4 (b) Crystallographically etched microstructures of copper rolled to $50 \%$ reduction in a single pass at room temperature. 


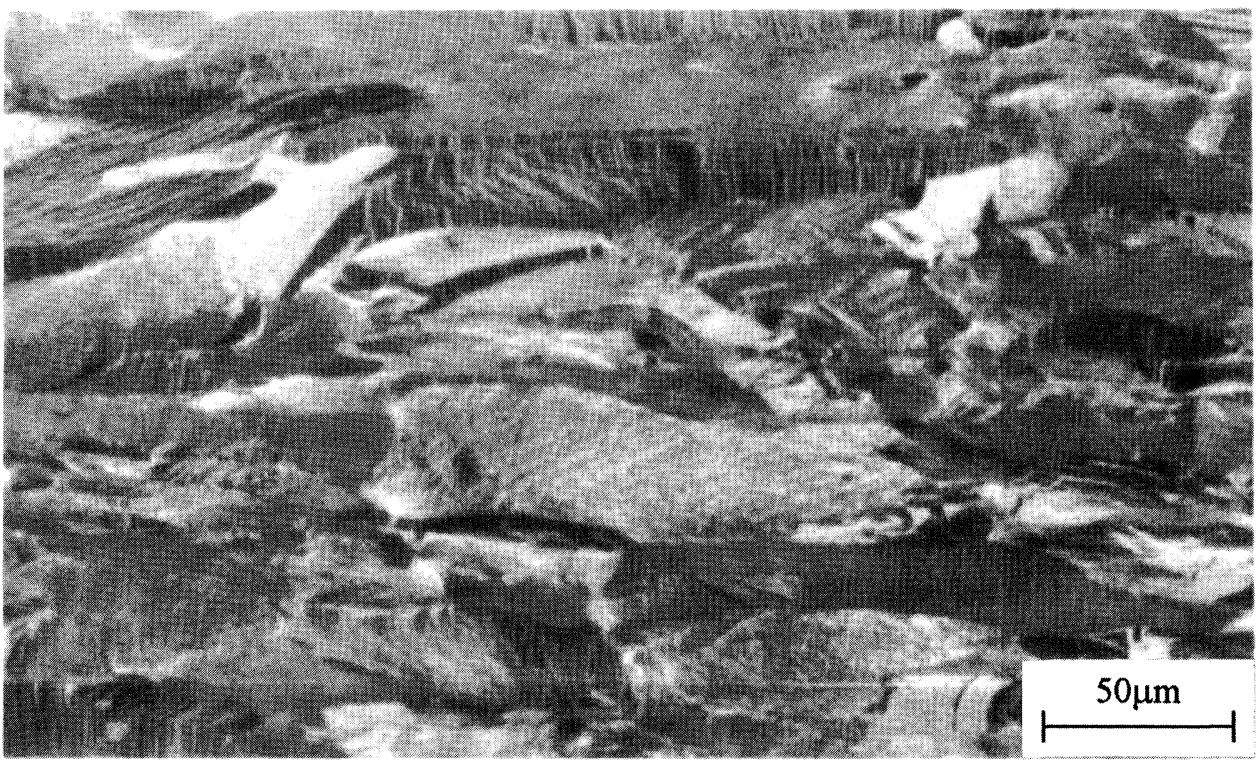

Figure 4 (c) Crystallographically etched microstructures of copper rolled to $50 \%$ reduction in a single pass at $350^{\circ} \mathrm{C}$.

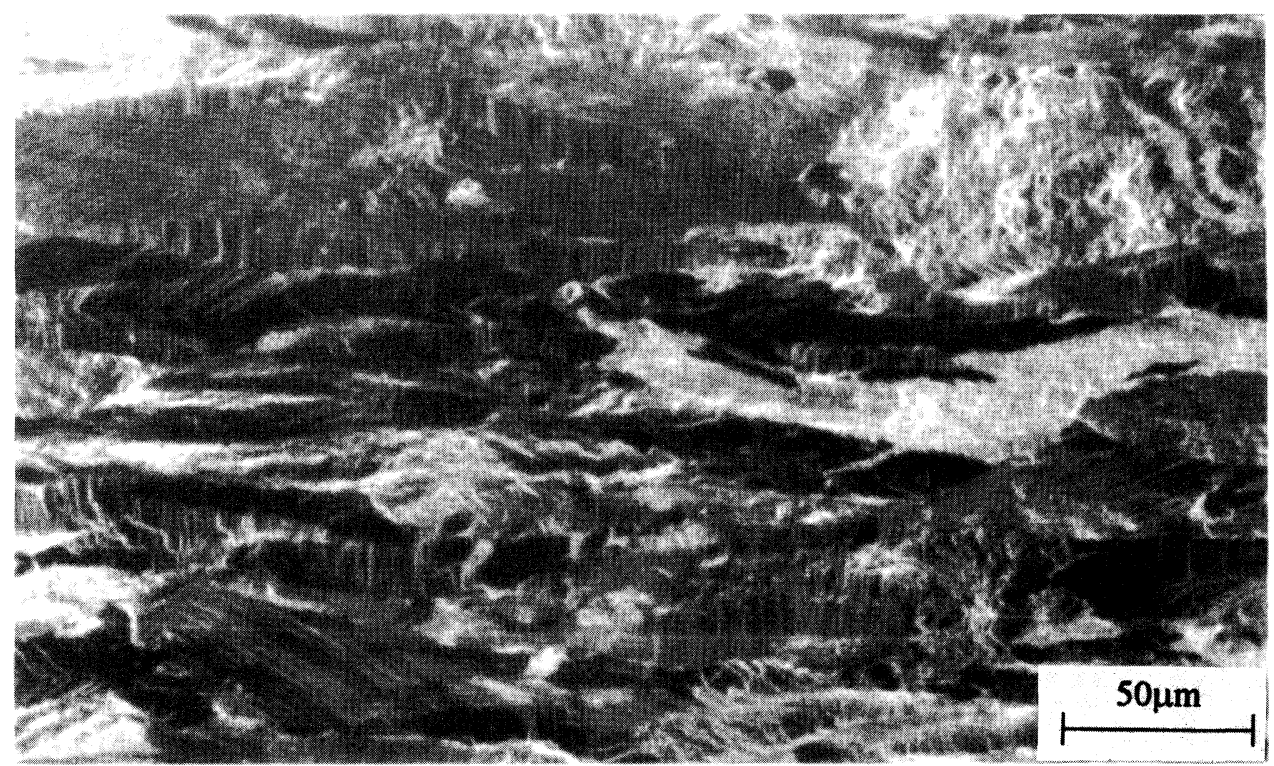

Figure 4 (d) Crystallographically etched microstructures of copper rolled to 50\% reduction in a single pass at $500^{\circ} \mathrm{C}$. 
(Figure 4d) are similar to those obtained at room temperature (Figure 4a) but are finer than those obtained in single pass rolling at room temperature (Figure $4 \mathrm{~b}$ ) and at $350^{\circ} \mathrm{C}$ (Figure $4 \mathrm{c}$ ). The $500^{\circ} \mathrm{C}$ microstructure resembles most closely the homogeneously rolled microstructure. At $75 \%$ strain, the microstructures developed are more complex, Figure 5. In the sample rolled at $500^{\circ} \mathrm{C}$, patches of dynamically recrystallized grains with orientations different to the deformed matrix are found, Figure 5c. They are also found in the sample rolled at $350^{\circ} \mathrm{C}$, but to a lesser extent, Figure $5 \mathrm{~b}$. In both rolling conditions, these dynamically recrystallized grains are found in original boundaries or deformation band boundaries and comprise less than $20 \%$ of the volume. The sample rolled at $500^{\circ} \mathrm{C}$ to $75 \%$ also exhibits a finer deformed structure than that at $350^{\circ} \mathrm{C}$, again similar to the room temperature, homogeneously rolled material, cf. Figure 5a and c.

Dynamically recrystallized grains found in single pass rolling at $500^{\circ} \mathrm{C}$ are shown in the TEM micrograph shown in Figure 6. Necklace structures are also found, Figure 7. The deformed structures show typical partially recovered equiaxed cells and microbands which are finer than those found in $350^{\circ} \mathrm{C}$ rolled samples, Figure 8 . These TEM results correspond well with the crystallographically etched samples. A similar correlation was found between the coarser structure indicated by Köhlhoff etching and TEM examination, i.e. deformation at $500^{\circ} \mathrm{C}$ produced a finer microstructure than that produced at $350^{\circ} \mathrm{C}$. It is therefore safe to conclude that deformation banding is prolific at room temperature under homogeneous rolling conditions, and also widespread at high rolling rates at $500^{\circ} \mathrm{C}$ up to a rolling strain of $75 \%$. However, deformation banding is not important under single pass rolling at temperatures up to $350^{\circ} \mathrm{C}$.

Deformation banding under homogeneous rolling conditions at slow strain rates is thought to occur because this mode reduces the Taylor work for the overall deformation, Lee and Duggan (1993a). In a later paper, Lee et. al. (1993b) theorised that dynamic

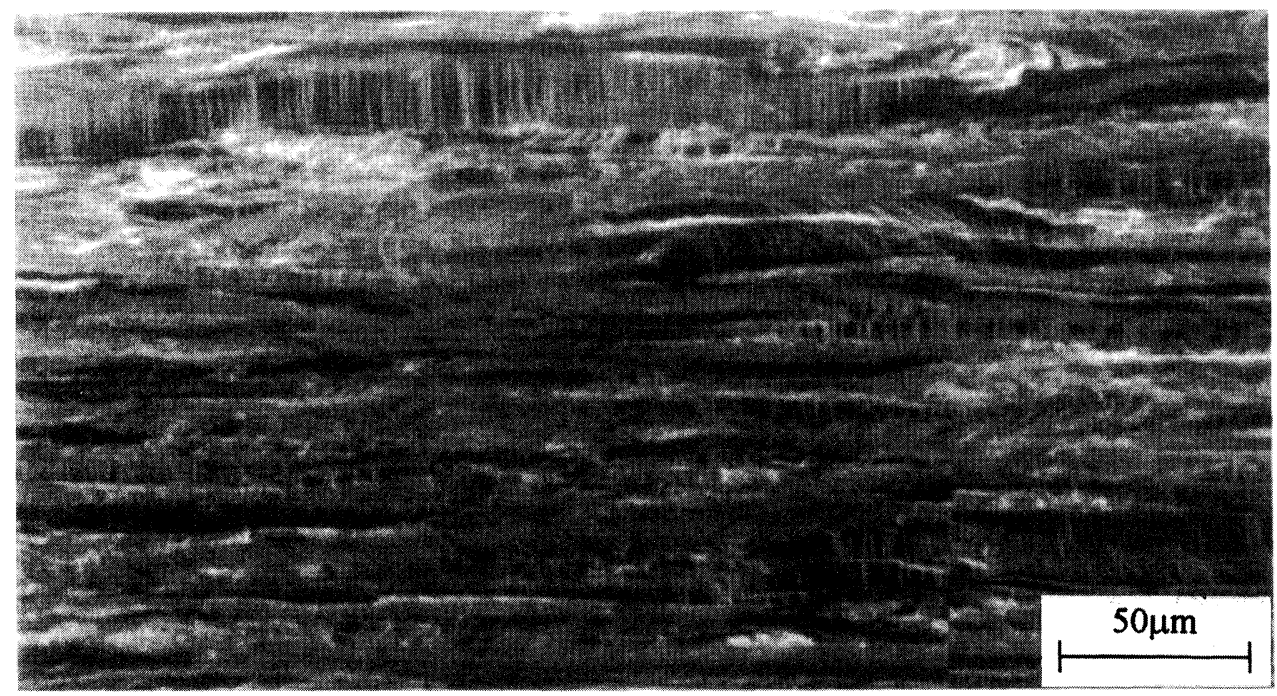

Figure 5 (a) Crystallographically etched microstructures of copper rolled to $75 \%$ reduction homogeneously at room temperature. 


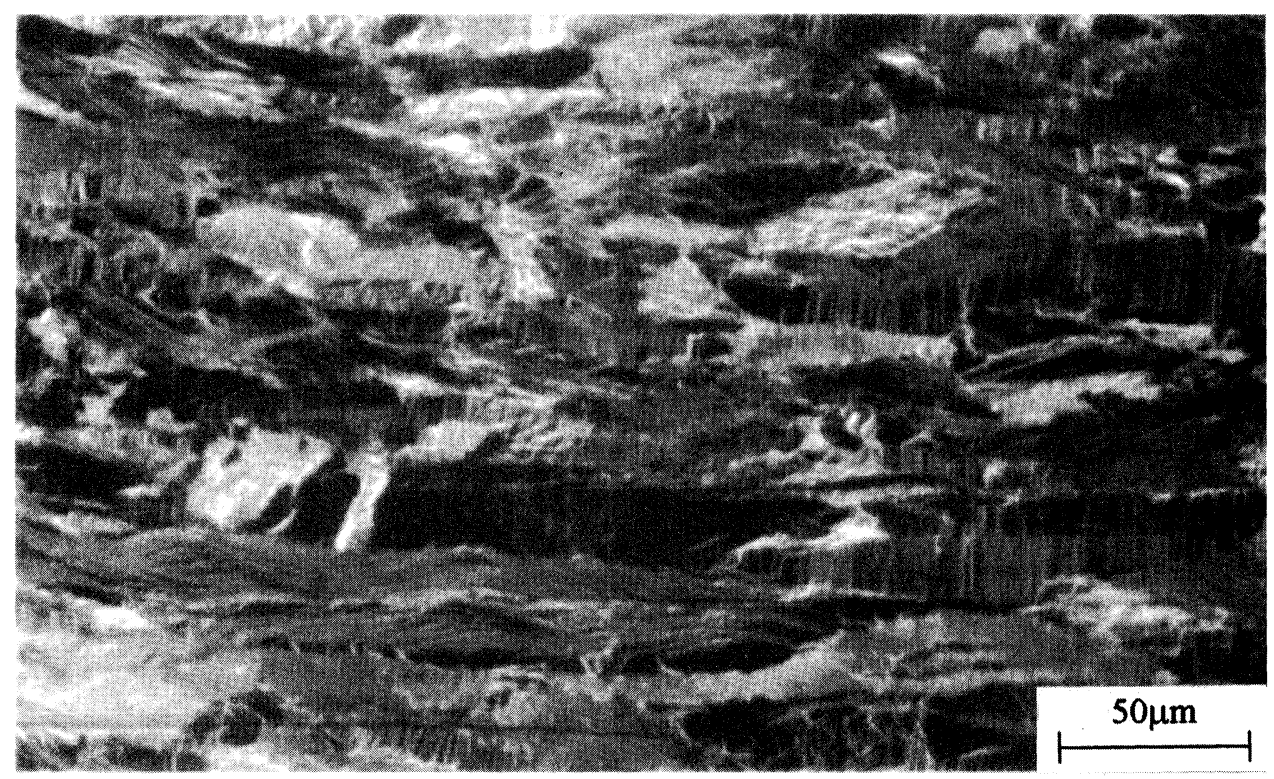

Figure 5 (b) Crystallographically etched microstructures of copper rolled to $75 \%$ reduction in a single pass at $350^{\circ} \mathrm{C}$.

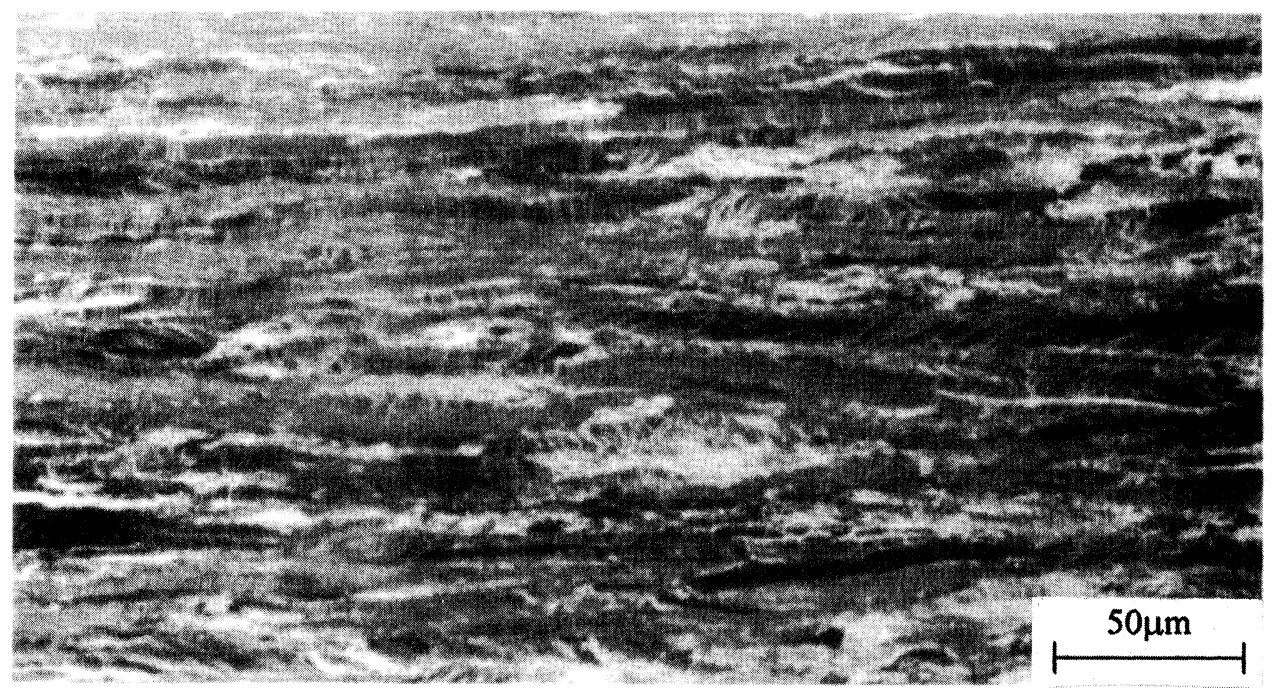

Figure 5 (c) Crystallographically etched microstructures of copper rolled to $75 \%$ reduction in a single pass at $500^{\circ} \mathrm{C}$. 


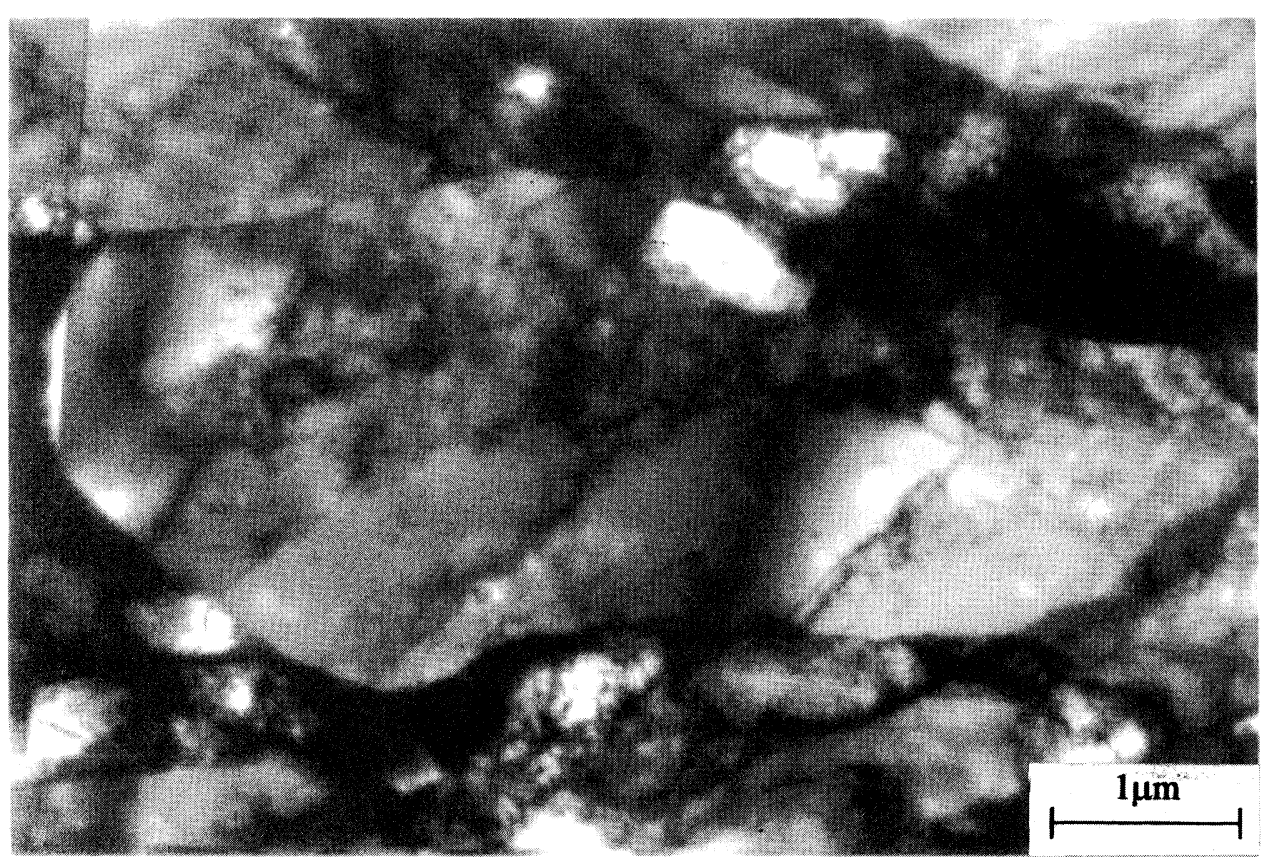

Figure 6 A dynamically recrystallized grain found in single pass rolling at $500^{\circ} \mathrm{C}$.

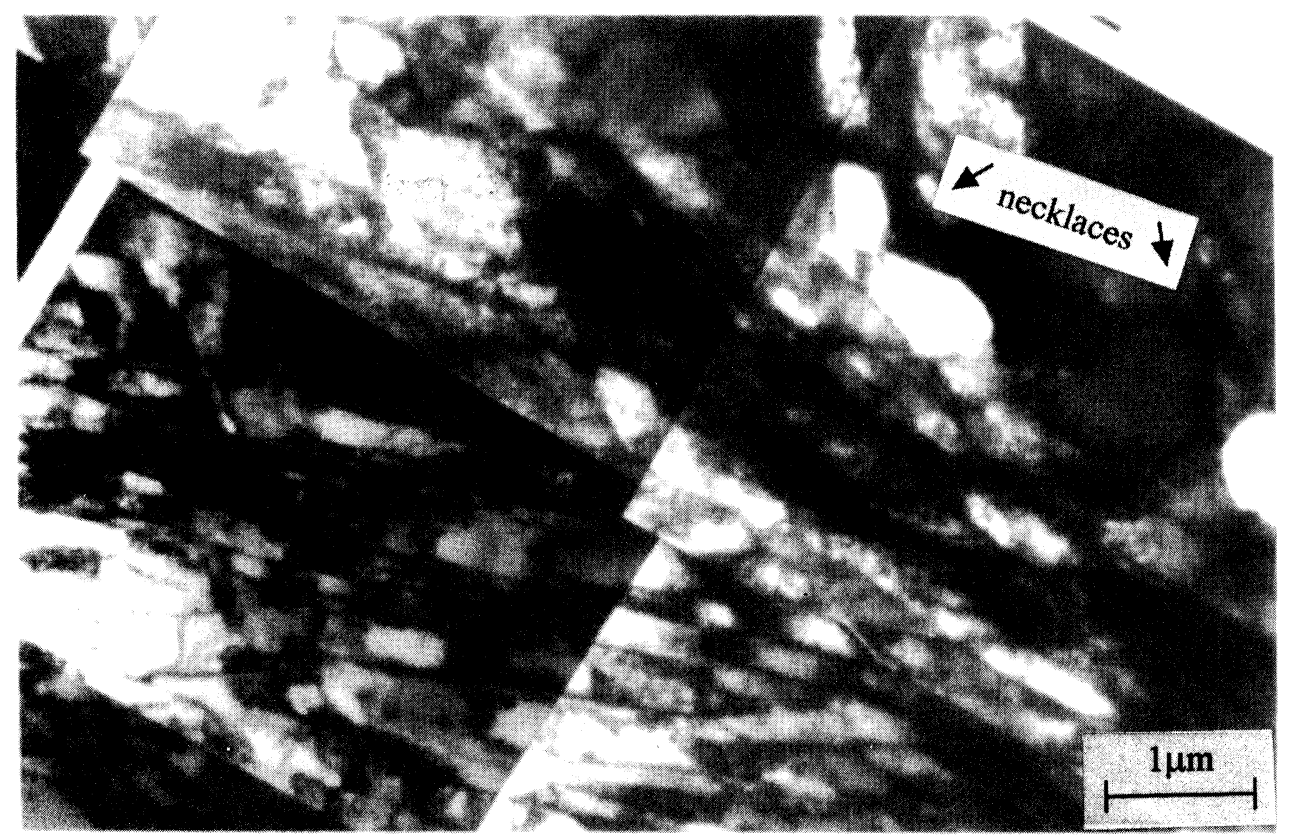

Figure 7 TEM micrograph of microstructure formed in single pass rolling at $500^{\circ} \mathrm{C}$. 


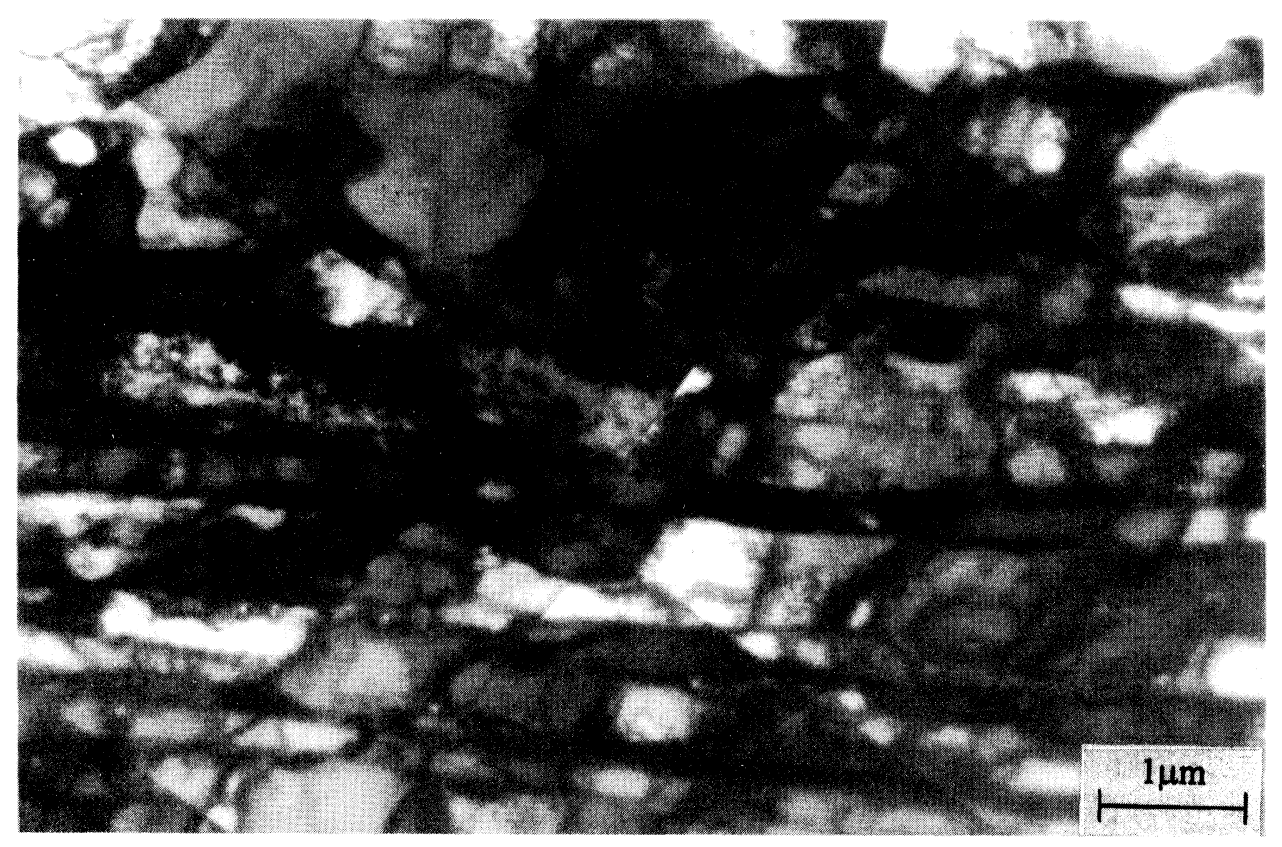

Figure 8 TEM micrograph of microstructure formed in single pass rolling at $350^{\circ} \mathrm{C}$.

recovery should allow constituent dislocation to arrange themselves into low energy wall structures, thereby enhancing the tendency of a crystal to form deformation bands. This idea was used earlier by Bacroix and Jonas (1988) to explain their warm rolling textures. The microstructures shown in Figure 5 support the idea that DB is enhanced at temperatures at which dynamic recovery and recrystallization would be confidently expected. It does not explain the room temperature results in Figure 4 which show $\mathrm{DB}$ at a strain rate of $6 \mathrm{sec}^{-1}$ and reduced DB at $25 \mathrm{sec}^{-1}$, which are similar to $\mathrm{Hu}$ and Cline's observations and which they ascribed to reduced turbulence of plastic flow at high rates of straining. Clearly slab widening cannot be important, given that DB is enhanced at $500^{\circ} \mathrm{C}$ under similar strain rates and widening. For high rates of straining, at low and intermediate temperatures where dynamic recovery is not operating, it is postulated that more slip systems are forced to operate that are strictly necessary on geometrical grounds and that some of these are non-octahedral systems. From this postulate it is inferred that less inhomogeneous deformation is necessary, thus allowing the crystals to retain their identities without recourse to inhomogeneous modes of deformation. Clearly, no evidence is presented here for this postulate, but work is continuing to see whether there is any proof of this idea. Equally clearly, such an idea has implications for the formation of textures under high rate conditions where dynamic recovery does not ameliorate the effects of high rate work hardening. The operation of many slip systems, including some non-octahedral ones, might well reduce texture sharpness. 


\section{CONCLUSIONS}

1. Textures formed in single pass rolling at room temperature to $500^{\circ} \mathrm{C}$ in copper are not as intense as under homogeneous rolling conditions.

2. Deformation banding behaviour is modified by both rate of deformation and temperature of rolling, being depressed by high rates and low temperatures of deformation.

3. Slab widening and rate of deformation cannot be separated yet in terms of explaining textures.

4. High rates of deformation at low temperatures produce structures and textures which might be explained by the operation of additional slip systems, some of which are assumed to be non-octahedral in character.

\section{Acknowledgement}

E. C. H. Lim gladly acknowledges the Department of Mechanical Engineering, The University of Hong Kong for financial support in the form of a Studentship.

\section{References}

Bacroix, B. and Jonas, J. J. (1988). The influence of temperature on deformature textures of FCC metals part III, the influence of dynamic recovery, Proceeding of ICOTOM 8, 423.

Barrett, C. S. (1939). Trans. AIME, 135, 296.

Barrett, C. S. (1939). Trans. AIME, 135, 296.

Chin, G. Y. (1969). Texture in Research and Practice, Springer, Berlin, 236.

Harris, J. N. (1983). Mechanical working of metals, Pergamon, 144.

Hu, H. and Cline, R. S. (1965). Trans Met. Soc, AIME, 233, 310.

Lee, C. S. and Duggan, B. J. (1991). A simple theory for the development of inhomogeneous rolling textures, Metal. Trans. A, 22A, 2637.

Lee, C. S. and Duggan, B. J. (1993a). Deformation banding and copper type rolling textures, Acta. Metall. Mater., 41(9), 2691.

Lee, C. S., Duggan, B. J. and Smallman, R. E. (1993b). A theory of deformation banding in cold rolling, Acta Metall. Mater., 41(8), 2265.

Raghunathan, N. and Sheppard, T. (1989). Lateral spread during slab rolling, Materials Sci. and Tech., $5,1021$. 